\title{
Numerical simulation analysis of the in-cavity residual stress distribution of lignocellulosic (wood) polymer composites used in shallow thin-walled parts formed by the injection moulding process
}

\begin{abstract}
In this paper, a numerical analysis of in-cavity residual stress formation in the thin-walled parts of injection-moulded parts is presented by considering the residual stresses produced during the post-filling stage. Injection moulding of shallow thin-walled parts with a thickness of $0.7 \mathrm{~mm}$ was performed using lignocellulosic polymer composites ( $\mathrm{PP}+50 \mathrm{wt} \%$ wood), and the parts have been systematically investigated using simulation results from Autodesk MoldFlow Insight ${ }^{\circledR}$ software. In-cavity residual stresses constitute the primary stage for analysis because of the need to control the quality of moulded parts to prevent problems with shrinkage and warpage. The analysis showed that the cooling times and packing times had a less significant effect; nevertheless, the optimal levels that are required to be used in the moulding process for thin-walled parts yielded better results. The in-cavity residual stress results show that the stress variation across the thickness exhibits a high tensile stress at the part surface, which changes to a low tensile stress peak value close to the surface, with the core region experiencing a parabolic tensile stress peak. The optimum parameter ranges for obtaining the minimum in-cavity residual stresses are as follows: a mould temperature of $40 \ddot{1}$ $45{ }^{\circ} \mathrm{C}$, a cooling time of $20 \mathrm{ï} 30 \mathrm{~s}$, a packing pressure of 0.85 Pinject, and a packing time of $15 \mathrm{I} 20 \mathrm{~s}$.
\end{abstract}

Keyword: Numerical simulation analysis; In-cavity residual stress; Lignocellulosic; Wood; Polymer composites; Injection moulding process 